\title{
ENTRE A IGUALDADE E A DIFERENÇA NOS DISCURSOS DO PROJETO SAÚDE E PREVENÇÃO NAS ESCOLAS
}

\author{
ENTRE LA IGUALDAD Y LA DIFERENCIA EN LOS DISCURSOS DEL \\ PROYECTO DE SALUD Y PREVENCIÓN EN LAS ESCUELAS
BETWEEN EQUALITY AND DIFFERENCE IN THE DISCOURSES OF THE PROJECT HEALTH AND PREVENTION AT SCHOOLS

\author{
Nathássia Matias de Medeiros ${ }^{1}$, Lorrana Caliope Castelo Branco Mourão ${ }^{1}$ \\ e Luciana Lobo Miranda ${ }^{1}$
}

${ }^{1}$ Universidade Federal do Ceará, Fortaleza/CE, Brasil

\begin{abstract}
RESUMO: A diversidade sexual tem sido uma questão amplamente discutida nos diversos espaços sociais, inclusive na escola. O objetivo deste artigo é analisar o discurso jurídico acerca da diversidade sexual presente nos materiais documentais do projeto governamental brasileiro chamado Saúde e Prevenção nas Escolas. Primeiramente, são expostos os elementos teóricos e metodológicos utilizados, inspirados sobretudo na concepção do discurso de Michel Foucault. Em seguida, é feita uma exposição e discussão dos resultados encontrados, em relação ao discurso jurídico presente nos materiais analisados. Problematiza-se a presença, nos documentos, de elementos baseados em recursos da justiça, como a igualdade entre os homens, respeito às diferenças e luta contra o preconceito e a "judicialização da vida". Por fim, apresentam-se algumas considerações finais que discutem o discurso em sua função de produção de realidades, questionando o duplo jogo da defesa da igualdade e as suas ciladas.
\end{abstract}

PALAVRAS-CHAVE: Igualdade social; Preconceito; Sexualidade.

RESUMEN: La diversidad sexual ha sido un tema ampliamente discutido en los distintos espacios sociales, incluyendo en la escuela. El propósito de este artículo es analizar el discurso jurídico sobre la diversidad sexual en el material documental del proyecto gubernamental brasileño llamado Salud y Prevención en las Escuelas. En primer lugar, se exponen los elementos teóricos y metodológicos utilizados, inspirados sobre todo en la comprensión del discurso de Michel Foucault. Luego, se exponen y discuten los resultados encontrados en relación con el discurso jurídico presente en los materiales analizados. Se problematiza la presencia, en los documentos, de elementos basados en recursos de la justicia, como la igualdad entre los hombres, el respeto a las diferencias y lucha contra el prejuicio y la "judicialización de la vida”. Por último, se presentan algunas consideraciones finales que discuten el discurso en su función de producción de realidades, cuestionando el doble juego de la defensa de la igualdad y sus trampas.

PALABRAS-CLAVES: Igualdad social; Prejuicio; Sexualidad.

ABSTRACT: Sexual diversity has been an issue broadly discussed in many social spaces, including at school. This article aims to analyze the legal discourse about sexual diversity present in the documental material of the Brazilian governmental project known as Health and Prevention at Schools. First, the article exposes the theoretical and methodological elements used, inspired especially by Michel Foucault's conception of discourse. Second, the article exposes and discusses the results found about the legal discourse present in the analyzed materials. It questions the presence, in the documents, of elements based on justice resources, such as equality between men, the respect for differences, and the fight against prejudice and the "judicialization of life." Finally, some final considerations that debate the discourse in its function as the production of realities are presented, questioning the double game of the defense of equality and its traps.

KEYWORDS: Social equality; Prejudice; Sexuality. 


\section{Introdução: sexualidade, diversidade e educação sexual nas escolas}

A diversidade sexual tem sido uma questão amplamente discutida não apenas dentro do espaço escolar, mas em toda a nossa sociedade. Segundo Santos et al. (2008), atualmente há um aumento expressivo dos debates e trabalhos acerca desta temática, principalmente em relação ao combate às discriminações, preconceitos e violências. Em paralelo a isso, observa-se uma crescente mobilização da sociedade civil organizada a favor do reconhecimento da legitimidade das diferenças.

Todos estes movimentos corroboraram na consolidação da educação para a diversidade sexual como uma das estratégias do Ministério da Educação (MEC) e da Organização das Nações Unidas para Educação, Ciência e Cultura (UNESCO), através de várias ações, como o programa "Brasil sem Homofobia" (2004) e o "Plano Nacional de educação em Direitos Humanos” (2003) (Santos et al., 2008). Muitas dessas políticas têm como objetivo promover a diversidade, seja de cor, de raça, de gênero, de etnia, de idade ou de origem sociocultural, e combater toda forma de preconceito, discriminação e violência (Junqueira, 2009).

No entanto, ao longo da história, a escola brasileira veio sendo consolidada a partir de pressupostos que tendem a reproduzir ideais de normatividade e de normalidade. Foucault (2011) insere a fabricação da norma e de diversas instituições, dentre elas a escola, na emergência da modernidade. Segundo o autor, a normalização disciplinar primeiramente expõe um modelo considerado como positivo em termos de bons resultados, para após definir o que pode ser dito como normal e anormal. Dessa forma, o poder disciplinar aponta a norma e a demarcação final do normal:

A normalização disciplinar consiste em primeiro colocar um modelo, um modelo ótimo que é construído em função de certo resultado, e a operação de normalização disciplinar consiste em tornar as pessoas, os gestos, os atos, conformes a esse modelo, sendo normal precisamente quem é capaz de se conformar com essa norma e o anormal que não é capaz. (Foucault, 2011, p. 75)

Ainda nos dias atuais, apesar de todos os esforços direcionados à luta contra os preconceitos e discriminações, é possível ainda observar no meio social a circulação do que podemos chamar de heteronormatividade. Sobre esse conceito, entendemos: "A heteronormatividade, desde uma perspectiva que enfatiza o caráter produtivo da linguagem, é problematizada como um padrão de sexualidade que regula o modo como a sociedade ocidental está organizada" (Petry \& Meyer, 2011, p.193). Fazem-se presentes também outros fatores que dialogam com esse caráter normativo, como o privilégio do adulto em detrimento da criança, do masculino em detrimento do feminino, dos brancos em relação aos negros, dentre outros. Dessa forma, todos os sujeitos que escapam à norma podem ser colocados à margem de uma educação que se pretenda para a maioria (Junqueira, 2009).

Em combate à heteronormatividade, têm-se produzido vários materiais, guias, manuais e outros documentos que se referem à diversidade sexual e visam a ser trabalhados no cotidiano escolar. Alguns desses materiais pertencem ao projeto Saúde e Prevenção nas Escolas (SPE), iniciado oficialmente em 2003. Trata-se de um projeto de abrangência nacional, referência de política pública no trabalho de educação sexual nas escolas. Em geral, ele tem como objetivo promover a saúde sexual dos jovens nas escolas (UNESCO \& MEC, 2010a). 
O SPE possui diversas publicações acerca das temáticas relacionadas à educação sexual, voltadas aos diversos personagens da comunidade escolar. Alguns dos temas trabalhados são: prevenção do HIV e Aids, diversidade sexual, gravidez na adolescência, protagonismo juvenil, entre outros. Estas publicações visam a guiar, facilitar e divulgar o projeto. Os documentos do SPE que são dirigidos à diversidade sexual têm como objetivo garantir a inclusão, promover a igualdade e enfrentar os preconceitos, as discriminações e as violências no contexto escolar, especialmente no que se relaciona ao gênero e às diferentes expressões da sexualidade (UNESCO \& MEC, 2010a).

O SPE aponta diversas "definições formais" para adolescência, evocando, por exemplo, a da Constituição Federal Brasileira, o Estatuto da Criança e do Adolescente - ECA (Lei Federal de 1990), a Organização Mundial da Saúde (OMS) e ainda o documento "Marco Legal: saúde, um direito de adolescente". Além desses artifícios jurídicos para a definição do que seria o adolescente, o projeto traz ainda vários outros enunciados para circunscrever a adolescência: discursos psicológicos, sociológicos, médicos etc.

$\mathrm{Na}$ cartilha "Diversidades sexuais: adolescentes e jovens para a educação entre pares", o termo "adolescente" é evocado sem distinção de sexo feminino ou masculino, como, por exemplo, neste trecho: "Acreditando que adolescente aprende mais com adolescente, o Ministério da Saúde e o Ministério da Educação, por meio do GTF, convocam adolescentes e jovens a intensificar o diálogo entre seus pares” (Min. da Saúde, 2011 b, p. 1). De uma forma geral, o termo também aparece fazendo relação com o Estatuto da Criança e do Adolescente (ECA).

Na cartilha "Gêneros", o termo continua aparecendo sem distinção de sexo masculino ou feminino. No entanto, existe uma passagem na qual a cartilha faz uma diferenciação entre"um" adolescente, do sexo masculino, e "a" adolescente do sexo feminino, para ilustrar as diferenças de gênero:

as desigualdades acontecem porque atribuímos valores diferentes para os comportamentos e as atitudes de homens e de mulheres. As desigualdades de gênero representam uma das maneiras de atribuirmos valor ao masculino e ao feminino. De modo geral, o masculino é mais valorizado em quase todas as sociedades. Um exemplo bem conhecido: um adolescente ou jovem heterossexual pode vivenciar sua sexualidade, ter vários relacionamentos sem que isso interfira na imagem que o grupo social terá dele. Ao contrário, a adolescente ou a jovem que tiver vários relacionamentos será julgada e chamada de "galinha". Meninos e meninas homossexuais e bissexuais, por sua vez, serão vistos como pessoas ameaçadoras, pois colocam em xeque as crenças e os valores de que só a heterossexualidade é "normal" (UNESCO \& MEC, 2011a, p. 16).

Há, nesse trecho, clara distinção entre os gêneros, relacionada aos papéis que homens e mulheres ocupam na sociedade. Ainda assim, a distinção entre "o" adolescente e "a" adolescente aparece com uma frequência muito pequena se comparar com a que o termo aparece sem distinção.

$\mathrm{Na}$ cartilha "Adolescências, juventudes e participação", há referência ao documento "Marco Legal: saúde, um direito de adolescentes" para explicar o termo adolescência. Observando o Marco Legal, é possível verificar a relação do termo com o ECA e com a Organização Mundial da Saúde: 
Art. 2. ${ }^{\circ}$ Considera-se criança, para efeitos desta Lei, a pessoa até doze anos de idade incompletos, e adolescente aquela entre doze e dezoito anos de idade ... A adolescência é a etapa da vida compreendida entre a infância e a fase adulta, marcada por um complexo processo de crescimento e desenvolvimento biopsicossocial. A Organização Mundial da Saúde circunscreve a adolescência à segunda década da vida (de 10 a 19 anos) e considera que a juventude se estende dos 15 aos 24 anos. Esses conceitos comportam desdobramentos, identifi cando-se adolescentes jovens (de 15 a 19 anos) e adultos jovens (de 20 a 24 anos). (Ministério da Saúde, 2007, p. 7)

Nota-se a partir disso que tanto o ECA quanto a Organização Mundial da Saúde não fazem distinção entre sexo feminino e sexo masculino quando se referem à adolescência e/ ou adolescente. Por exemplo, ainda na cartilha "Adolescências, juventude e participação", o documento faz novamente referência ao ECA quando fala de adolescente, e não faz diferença entre gênero:

Está no ECA! ... Art. 11. É assegurado atendimento integral à saúde da criança e do adolescente, por intermédio do Sistema Único de Saúde, garantido o acesso universal e igualitário às ações e serviços para promoção, proteção e recuperação da saúde ... A criança e o adolescente portadores de deficiência receberão atendimento especializado (UNESCO \& MEC, 2011d, p. 43).

Portanto, é possível afirmar que o SPE aponta diversas "definições formais" para adolescência, evocando a Constituição Federal Brasileira, o Estatuto da Criança e do Adolescente - ECA (Lei Federal de 1990), a Organização Mundial da Saúde (OMS) e o documento "Marco Legal: saúde um direito de adolescente".

Apesar do projeto constantemente unificar homens e mulheres no uso de um só termo: “adolescente", ele traz especificidades nos modos de exercícios de poder sobre moças e rapazes através de seus discursos, como foi possível observar acima, no exemplo da Cartilha "Gêneros". De uma forma geral, como discutido anteriormente, o projeto utiliza o termo adolescente sem distinção de gênero. Ao longo do artigo será possível observar o uso desse termo sem distinção, uma vez que estaremos trabalhando com os documentos do SPE.

Lançando um olhar sobre esse projeto governamental, pode-se dizer que o SPE é uma iniciativa que acontece dentro do território escolar. No entanto, nos parece importante não tomar como natural essa presença de discussões sobre sexualidade adolescente nas escolas, mas sim como algo que foi construído historicamente. Segundo Foucault (1988), apenas por volta do século XVIII, com a expansão da instituição escolar na Europa, que a temática do sexo passa a estar presente nas escolas e a sexualidade dos alunos torna-se um problema público. A medicina começa a intervir junto aos diretores, professores e pais, enquanto pedagogos elaboram projetos e professores fazem recomendações aos alunos. A partir disso, há uma intensa produção de discursos em torno da sexualidade dos estudantes.

No contexto do Brasil, principalmente após a incidência da Aids como uma grande epidemia e após o aumento da taxa de fecundidade, entre 1980 a 2000, em mulheres de 15 a 19 anos, temas ligados à sexualidade adolescente passaram a ser inseridos com maior ocorrência nas discussões e planejamentos educacionais (Altmann, 2006).

Um momento importante que contribuiu para a responsabilização da escola pela educação sexual de seus alunos foi o estabelecimento, em 1996, dos Parâmetros Curriculares 
Nacionais (PCN), que determinam a educação sexual como um tema a ser trabalhado em todas as matérias escolares. "Quanto às questões sociais relevantes, reafirma-se a necessidade de sua problematização e análise, incorporando-as como temas transversais. As questões sociais abordadas são: ética, saúde, meio ambiente, orientação sexual e pluralidade cultural” (Ministério da Saúde, 1997, p. 41). Após os PCN, várias outras iniciativas de educação sexual, governamentais ou não, surgiram.

Atualmente, a educação sexual é promovida através de iniciativas provenientes de múltiplos meios, tais como programas sociais, políticas públicas, mídia, não estando presente apenas na escola (Altmann \& Martins, 2009). Contudo, é possível considerar que a dimensão escolar ainda possui relevância, sendo essa uma das veiculadoras da educação sexual. Altmann (2001) destaca que pesquisas chegam a afirmar que quanto menor é a escolaridade das adolescentes, maior é o índice de gravidez entre elas.

A escola pode ser compreendida como um dos grandes locais de desenvolvimento do biopoder. Esse é entendido como uma forma de exercício de relações de poder que surgiu no Ocidente a partir do Século XVII, buscando exercer-se sobre a vida através de dois polos: as disciplinas do corpo e as regulações da população (Foucault, 1988). Inspirada no pensamento de Michel Foucault (1926-1984), Altmann (2007) afirma que este desenvolvimento acontece, entre outras formas, através do controle da sexualidade das crianças e, principalmente, dos adolescentes. Foucault é um importante filósofo que pensa as questões que articulam biopoder e sexualidade, e oferece ferramentas para problematizá-las, tendo escrito três volumes sobre a história da sexualidade (Foucault, 1988, 1984, 1985) e vários outros textos e entrevistas sobre os assuntos. É no campo do pensamento desse autor que se situa o olhar teórico desta pesquisa.

As ações de educação sexual que podemos encontrar atualmente, dentre elas o projeto Saúde e Prevenção nas Escolas, estabelecem várias temáticas a serem trabalhadas na educação formal. Um dos grandes temas de tais iniciativas é a diversidade sexual. Quartiero e Nardi (2011) explicam que o termo diversidade sexual tem sido utilizado principalmente para designar questões relacionadas às homossexualidades. No contexto educacional, o termo frequentemente se insere no campo da inclusão, que busca combater as discriminações.

Há também numerosas iniciativas na área da educação que visam à igualdade de gênero, identidade de gênero, orientação sexual, combate ao sexismo e à homofobia. Segundo os mesmos autores, todas essas iniciativas são baseadas em ações governamentais relativas à educação, ações essas que estão presentes no Programa Nacional de Direitos Humanos II (2002), no Plano Nacional de Políticas para as Mulheres (2004), no Programa Brasil sem Homofobia (2004) e no Plano Nacional de Educação em Direitos Humanos (2006). Segundo os autores supracitados, em 2004, aconteceram os lançamentos do Plano Nacional de Políticas Públicas para as mulheres e do Programa Brasil sem Homofobia. Ambos foram frutos dos vários debates sobre a elaboração e operacionalização de políticas voltadas às mulheres e à população LGBTT (Lésbicas, gays, bissexuais, travestis e transexuais e transgêneros). Esses programas objetivavam uma educação inclusiva e propunham ações no campo da educação através da produção de materiais didáticos e formação de professores. A existência dessas várias iniciativas reforça a ideia de que a sexualidade dos adolescentes é alvo de grande investimento social, e várias ações são desenvolvidas no sentido de geri-la.

Atualmente, a sexualidade ainda é controlada por mecanismos que tornam o indivíduo e a população objetos de saber e poder. Esses mecanismos, como apontam Dinis 
e Asinelli-Luz (2007), voltam-se principalmente para as sexualidades de grupos chamados periféricos, como adolescentes, crianças, mulheres e homossexuais, e a escola parece ser um grande espaço de operação desse controle. Assim, é fundamental que se pense sobre os discursos e as práticas escolares atuais acerca da diversidade sexual. Quartiero e Nardi (2011) explicam que o termo diversidade, que tem sido usado em substituição aos termos "diferente" ou "diverso", contém em si o referencial de normal. Com isso, estabelece-se o lugar da "diversidade", a ser ocupado por aqueles que escapam à norma sexual (predominantemente heteronormativa), conforme aponta o autor:

Ao pensar as políticas públicas que hoje propõem trabalhar a diversidade sexual, percebe-se que os discursos veiculados por tais campanhas sugerem, implícita ou explicitamente, concepções de sexualidade [grifo nosso]. Nesse sentido, também se pode entender essas campanhas de órgãos públicos como inseridas num discurso de fabricação de sujeitos e de sexualidades desejáveis, juntamente com o de aceitação de sexualidades nem tão desejáveis, traduzindo-se por propostas de políticas de inclusão. (Quartiero \& Nardi, 2011, p. 71)

Observa-se, nos documentos do SPE, um tipo de sexualidade que é construído em função de um certo resultado, e ao mesmo tempo um desejo de tornar os adolescentes conforme esse modelo, sendo normal o que consegue se encaixar à sexualidade desejável, e anormal o que não consegue, sendo que o último vem a ocupar esse lugar de "diversidade sexual", e, o normal aquele que deve, a todo custo, aceitar o anormal, o "diverso".

O SPE evoca diversos discursos para construir um saber e uma prática sobre a diversidade sexual em seus materiais publicados. Em outras palavras, ele traz enunciados de discursos, como o discurso médico, o discurso jurídico ou o discurso psicológico, para falar sobre a diversidade sexual e propor ações educativas com os adolescentes. Neste artigo, analisaremos a presença do discurso jurídico nos materiais do projeto SPE.

Ao abordar a diversidade sexual dos adolescentes em seus materiais publicados, o SPE evoca diversos discursos para construir um saber e uma prática sobre esse objeto. Em outras palavras, ele traz enunciados de discursos, como o discurso médico, o discurso jurídico ou o discurso psicológico, para falar sobre a diversidade sexual e propor ações educativas com os adolescentes. Neste artigo, analisaremos a presença do discurso jurídico nos materiais do projeto SPE.

Dessa maneira, o objetivo deste artigo é analisar o discurso jurídico acerca da diversidade sexual presentes nos materiais documentais do projeto Saúde e Prevenção nas Escolas através dos pressupostos teórico-metodológicos da análise do discurso baseada no pensamento do filósofo francês Michel Foucault. No primeiro subtópico, exporemos os elementos teórico-metodológicos utilizados. No segundo, faremos uma breve exposição dos resultados encontrados. Nos tópicos seguintes, teceremos uma discussão sobre os resultados, problematizando como o discurso jurídico se articula com o tema da diversidade sexual no SPE. Por fim, apresentaremos algumas considerações finais. 


\section{Caminhos teórico-metodológicos}

Uma vez que o SPE é um projeto de educação sexual nas escolas, seus materiais contemplam várias questões relacionadas à sexualidade adolescente que devem ser trabalhadas no ambiente escolar. Assim, a discussão sobre a diversidade sexual está presente apenas em alguns dos materiais divulgados pelo projeto. Neste artigo, foram analisados todos os documentos do SPE que abordam a diversidade sexual em seu conteúdo e que estão disponíveis para download na internet nos sites da UNESCO e do Fundo das Nações Unidas para a Infância (UNICEF). Os documentos analisados neste artigo são: guia para a formação de profissionais de saúde e de educação (Ministério da Saúde, 2006); guia para utilização das HQ SPE em sala de aula (UNESCO \& MEC, 2010a); HQ SPE (História em Quadrinhos Saúde e Prevenção nas Escolas), dos números 1 ao 6 (UNESCO \& MEC, 2010b, 2010c, 2010d, 2010e, 2010f, 2010g); e seis manuais ("Gêneros: adolescentes e jovens para a educação entre pares.", "Diversidades sexuais: adolescentes e jovens para a educação entre pares.", "Sexualidades e Saúde Reprodutiva: adolescentes e jovens para a educação entre pares.”, "Adolescências, Juventudes e Participação: adolescentes e jovens para a educação entre pares.", "Raças e Etnias: adolescentes e jovens para a educação entre pares.", "Prevenção das DST, HIV e Aids: adolescentes e jovens para a educação entre pares.") (Ministério da Saúde, 2011a, 2011 b, $2011 \mathrm{c}, 2011 \mathrm{~d}, 2011 \mathrm{e}, 2011 \mathrm{f}$ ).

Para problematizar como os diferentes discursos atravessam os materiais do SPE e possibilitam a constituição de um discurso próprio da diversidade sexual, trabalharemos com a análise do discurso baseada no pensamento de Michel Foucault (Foucault, 1986, 2012). Esta concepção entende o discurso enquanto uma prática, analisando o seu funcionamento dentro de configurações de saber-poder de determinada época (Araújo, 2004). Segundo Veiga-Neto (2009), na análise de discurso não se trabalha com um método, mas sim como uma atividade, uma maneira de entender ou um modo de ver as coisas.

Conforme Fairclough (2001), o discurso é uma preocupação de Foucault durante toda a sua obra, mas seu status é reformulado. Na arqueologia, que corresponde ao primeiro momento de obra de Foucault, o foco reside nas modalidades de discurso, que servem como regras para construir áreas de conhecimento. Já na genealogia, que corresponde ao segundo momento, a ênfase passa a repousar nas relações entre poder e conhecimento. Foucault substitui a noção de epistème pela ideia de dispositivo e depois amplia para concepção de prática (Castro, 2009). Tal movimento faz com que a análise do discurso passe a se ocupar mais com a análise do caráter não-discursivo.

Araújo (2004) afirma que, para a análise do discurso baseada em uma perspectiva foucaultiana, a linguagem não é representativa nem essencialista. Pelo contrário, a linguagem cria novas realidades. Neste ínterim, busca-se estabelecer um olhar histórico sobre os objetos discursivos que considere que os discursos constroem os objetos sobre os quais enuncia.

Segundo Foucault (1986) discurso é um agrupamento de enunciados que se apoiam na mesma formação discursiva. Essa, por sua vez, é o conjunto de regras de divisão e dispersão dos enunciados, que vai determinar o que pode ser dito e onde pode ser dito. 
No caso em que se puder descrever, entre um certo número de enunciados, semelhante sistema de dispersão, e no caso em que entre os objetos, os tipos de enunciação, os conceitos, as escolhas temáticas, se puder definir uma regularidade (uma ordem, correlações, posições e funcionamentos, transformações), diremos, por convenção, que se trata de uma formação discursiva. (Foucault, 1986, p. 47)

Deleuze (2005) assinala que a formação discursiva é histórica, pois somente determinada época pode produzi-la e nenhuma formação é igual à outra. Pensar nessa perspectiva é perguntar-se sobre os regimes de verdade da época que tornam possível que determinado discurso se sustente e sobre como está ligado às relações de poder e saber dessa época. O discurso é também prática, formado por regras históricas que definem as condições de exercício da função enunciativa (Foucault, 1986).

Assim, o trabalho da análise do discurso com orientação foucaultiana parte de sua aparição e regularidade, em direção às suas condições de possibilidade exteriores. Nesta pesquisa, isto significa se perguntar sobre os regimes de verdade da época que tornam possível que o discurso jurídico sobre diversidade sexual produzido nos materiais do SPE se sustente e como se encontra ligado às relações de poder e saber da atualidade, sobretudo no ambiente escolar.

\section{O saber/poder jurídico e o direito à diversidade sexual}

É possível perceber que o discurso jurídico, representado pelas leis que cercam a adolescência e juventude, atravessa o projeto Saúde e Prevenção nas Escolas e fala através dele. A lei passa por algumas questões discutidas no SPE, como leis contra o uso de drogas ilícitas, leis contra a violência e leis relacionadas à diversidade sexual. O projeto dá visibilidade a esses enunciados legislativos com a finalidade de sustentar, validar, reafirmar o seu próprio discurso acerca da sexualidade adolescente.

Dessa maneira, podemos dizer que o projeto evoca leis e enunciados de cunho jurídico com a finalidade de embasar o que é dito em seus vários materiais documentais. Por exemplo: "O Estatuto da Criança e do Adolescente, como foi denominada a Lei Federal n 8.069, de 13 de julho de 1990, é uma lei com 267 artigos que trata sobre a proteção integral às crianças e aos adolescentes de todo o Brasil” (UNESCO \& MEC, 2010a, p. 31).

Nos enunciados sobre diversidade sexual analisados nos materiais, o discurso jurídico emerge com força e presença constante. As leis e os direitos dos adolescentes são apresentados ao se falar sobre igualdade, respeito às diferenças, preconceito, discriminação e algumas outras questões que são relacionadas pelo projeto ao tema da diversidade sexual. O discurso da igualdade aparece com constância ao longo do material analisado, encontrando-se atrelado a outras questões, como ao respeito à diversidade sexual, ao enfrentamento das discriminações e à luta contra o preconceito e a violência, como podemos visualizar no trecho abaixo:

no que diz respeito à diversidade sexual, ainda existe um longo caminho pela frente. Para muita gente, ainda é muito complicado aceitar que existem várias possibilidades de relacionar afetivamente e/ou sexualmente com outras pessoas, independente do sexo. A heterossexualidade continua sendo considerada, por 
muitos(as), como a única referência possível de vivência da sexualidade ... como um espaço de formação de cidadãos e cidadãs, cabe à escola trabalhar a aceitação às diversidades e pensar em estratégias de enfrentamento a qualquer tipo de preconceito e discriminação (UNESCO \& MEC, 2010a, p. 46).

Ora, mas como trabalhar para aceitar as diversidades e enfrentar o preconceito e as discriminações? O SPE parece responder: as desigualdades devem ser combatidas: "as desigualdades de gênero se refletem nas leis [grifo nosso], políticas e práticas sociais, assim como nas identidades, atitudes e comportamentos das pessoas" (UNESCO \&MEC, 2010a, p. 19). Dessa forma, segundo os documentos, as diversidades sexuais não podem ser transformadas em desigualdades. Um dos materiais, por exemplo, "traz uma série de oficinas e textos sobre discussões de gêneros, a partir de um enfoque para a promoção da saúde e igualdade” (Ministério da Saúde, $2011 \mathrm{a}$, p. 11, grifo nosso).

O SPE busca, através da noção de igualdade, uma discussão para além da orientação sexual do sujeito, seja homossexual, bissexual ou heterossexual e para além do gênero. A forma como os sujeitos decidem se relacionar e se perceber não pode se transformar em desigualdade, preconceito, discriminação, violência etc. "Ninguém discorda que homens e mulheres possuem diferenças. O que não podemos é contribuir para que essas diferenças sejam transformadas em desigualdades” (Min. Saúde, 2011, p. 16, grifo nosso).

A igualdade entre os homens é uma questão de direito, pois é garantida por diversas leis, sendo uma questão jurídica. A té hoje, o grande documento que é referenciado quando se fala em igualdade é a Declaração Universal dos Direitos Humanos, que foi adotada pela Organização das Nações Unidas em 1948. O artigo $7^{\circ}$ da Declaração (ONU, 1948) preconiza que todos são iguais perante a lei e por conta disso possuem direito a igual proteção, inclusive contra qualquer discriminação que viole a própria Declaração.

Segundo Lafer (1995), ao longo do tempo as primeiras afirmações em torno dos direitos dos homens se deu com as Revoluções Americana e Francesa no séc. XVIII. Antes, no âmbito político, existia uma discussão sobre o bom governo. Como a tirania soberana prevalecia, vários pensadores haviam se preocupado em buscar meios para derrotá-la, propondo, por exemplo, a divisão de poderes. Nesse caso, o foco era sempre os governantes. A partir das revoluções, houve uma ênfase na promoção dos direitos do cidadão, a partir da ideia do "direito de ter direitos", como uma base dos regimes democráticos contemporâneos. O governante, assim, passou a ter o seu poder limitado e foi plenamente instaurado o liberalismo. A partir disso, era melhor "contar cabeças do que cortar cabeças". Assim, considerou-se mais importante os conceitos de dignidade humana e de universalidade, a despeito de qualquer particularismo, inaugurando o Homem Universal.

Para Maliska e Wolochn (2013), a ideia de igualdade como direito surge relacionada principalmente ao ideal de liberdade. Como afirmado por Lafer (1995), os direitos de liberdade foram promulgados principalmente a partir dos ideais da Revolução Burguesa e Americana dos séculos XVII e XVIII. No entanto, ainda que as declarações e cartas de direito tenham dito que todos os homens são iguais e livres, naquela época as desigualdades ainda eram bastante evidentes. Mulheres, pobres, analfabetos não participavam da vida política. Para tanto, a Revolução Francesa eliminou o absolutismo e o dogmatismo, porém não solucionou as grandes desigualdades sociais. Destarte, alguns movimentos revolucionários socialistas pregavam a necessidade da igualdade geral, apontando as desigualdades econômicas e sociais da era capitalista. 
A partir desses movimentos surgiu uma maior reivindicação a respeito de outras necessidades sociais e o pedido para que a igualdade fosse relacionada aos mais diversos fatores sociais, como os econômicos, políticos, sociais, de gênero, dentre outros. Aos poucos, algumas mudanças ocorriam como a introdução do voto universal e direitos econômicos e sociais foram postos na legislação. Assim, a exigência do Estado na intervenção do bem-estar social foi cada vez maior, a fim de diminuir as desigualdades (Maliska \&Wolochn, 2013).

No Brasil, a igualdade é colocada como um ideal a ser alcançado na saúde, no convívio social, nas aplicações das leis, no campo educacional, entre outros espaços. De acordo com o artigo $5^{\circ}$ da Constituição Da República Federativa Do Brasil, instituída em 1988, todos são iguais perante a lei, sem distinção de qualquer natureza. Não é apenas a Constituição Federal do Brasil que visa a garantir a igualdade entre os brasileiros (Senado Federal, 1988); cada vez mais surgem leis, que resultam de lutas políticas principalmente de grupos minoritários, que vão buscar a igualdade, sempre a atrelada à luta contra discriminação e exclusão das pessoas consideradas "diferentes". Busca-se a garantia de ser igual. No projeto Saúde e Prevenção nas Escolas, nota-se que essa reivindicação faz-se constantemente presente: "Para que as mulheres possam exercer seus direitos, é necessário um ambiente legal e político que seja favorável à igualdade e à equidade entre os gêneros. A igualdade entre os gêneros é essencial para que as mulheres tenham voz ...” (M. da Saúde, 2011a, p. 56). Também aponta-se o problema da manutenção de determinadas desigualdades:

As relações de gênero, quando desiguais, tendem a aprofundar outras desigualdades sociais e econômicas e contribuem para a manutenção de contextos, atitudes e comportamentos violadores dos direitos humanos, tais como a discriminação em função da classe socioeconômica, nível de escolaridade, raça e etnia, idade, orientação sexual, condições de saúde ou deficiência, dentre outras. (Min. da Saúde, 201 1a, p. 19)

Todavia, como já esclarece e problematiza Pierucci (1995), a igualdade tem suas ciladas, já que a concepção de Homem Universal apregoada pelos ideais de igualdade é simplificadora e redutora da natureza humana, da vida social e da ordem política. Segundo o autor, essa postura denota uma certa abstração das particularidades: "O homem universal é o resultado histórico de um desnudamento: ele surge historicamente quando despojado do valor das suas diferenças culturais. Quando desvalorizado em sua diferença” (Pierucci, 1995, p. 21).

Para Pierucci (1995), o direito à igualdade é um símbolo apregoado pelas esquerdas, enquanto o direito à diferença tem sido mais reforçado pela direita política. Vindo com um semblante muito mais sedutor, o clamor pela diferença é muito mais perigoso do que pela igualdade. Para tanto, não é difícil observar esses discursos sendo aclamados no SPE, principalmente quando são ligados ao combate ao preconceito e à discriminação. O elogio à diferença carrega uma grande força de sedução e maior facilidade de penetração, surgindo como uma nova palavra de ordem, novas reinvindicações, novas atitudes. No SPE, encontramos a seguinte afirmação, que indica a diversidade como ditame: "As oficinas propostas neste módulo têm como base que a diversidade é a norma e não a exceção" (UNESCO \& MEC, 2010a, p. 50, grifo nosso).

Nos materiais do SPE analisados, foi possível observar que a diversidade é colocada como algo que deve ser respeitado sempre e é objetivo do projeto promover tal respeito. "Enfim, reconhecer e valorizar a diversidade humana é condição fundamental para uma 
ação educativa. Será este o desafio que professores, coordenadores pedagógicos e diretores terão pela frente" "- Fabinho: Eu não estou falando de negar ou aceitar que as pessoas sejam diferentes, estou falando de respeito às diferenças".

Observamos, de acordo com a fala de Fabinho, a necessidade do respeito às diferenças. Aqui, o respeito sai da igualdade e entra na diferença. Para Pierucci (1995, p. 7), atualmente temos a seguinte questão:

... somos todos iguais, ou somos todos diferentes? Queremos ser iguais ou queremos ser diferentes? Houve um tempo em que a resposta se abrigava, segura de si, no primeiro termo da disjuntiva. Já faz um quarto de século, que a resposta se deslocou ... somos diferentes de fato ... mas somos também diferentes de direito. É o chamado "direito à diferença” Não queremos mais a igualdade, parece.

Em suma, observamos que, no projeto Saúde e Prevenção nas Escolas, a valorização da diversidade e o combate aos preconceitos entram em um espaço discursivo em que ora opera a igualdade, ora a diversidade / diferença, buscando promover principalmente o ideal de paz, liberdade e tolerância nas relações humanas. Nesta política discursiva que o projeto SPE promove há todo um trabalho de não opor igualdade à diferença, mas sim à desigualdade.

\section{O discurso jurídico do SPE: problematizações sobre a judicialização da vida}

Para além da igualdade e da diferença, observamos principalmente no texto do SPE o discurso do direito a, isto é, a ideia de que todas as pessoas devem ter direito a terem direitos: "Isso significa que não faz diferença se a mulher agredida mantém relações com homens ou mulheres, os seus direitos estão assegurados de qualquer modo.” (Min. da Saúde, 2011a, p. 46). O SPE também afirma: “... todas e todos merecem igual respeito da lei, dos governantes e das pessoas em geral, independentemente de seu sexo biológico, da identidade que assumam ou do papel social que exerçam.” (Min. da Saúde, 2011c, p. 14). No entanto, há também deveres a cumprir. Ao falar sobre pessoas preconceituosas, o projeto aponta: "Essas pessoas têm muita dificuldade em conviver democrática e respeitosamente com a diversidade e de reconhecer que quem é diferente tem os mesmos direitos [grifo nosso] e deveres, na vida pessoal e em coletividade” (Min. da Saúde, 2011 b, p. 13).

Destarte, os que se sentem em uma posição inferior e desfavorecida em relação ao não cumprimento da lei, clamam pela sua efetivação. No SPE essa questão se faz presente: "Leis e políticas que visam à igualdade e equidade entre os gêneros na distribuição de recursos, na participação política e na tomada de decisões tem impactos positivos na saúde sexual e reprodutiva das mulheres ...” (Min. da Saúde, 2011 a, p. 56). O ilegalismo agora gira em torno daquele que pratica a ilegalidade: "Você não pode fazer isso, isso é contra lei". Essa judicialização da vida gera o corpo social e engendra cada vez mais nossas relações.

De uma forma ou de outra, existe uma emergência em torno do cumprimento da lei no âmbito jurídico, sendo muito comum encontrar essa discussão no corpus da escola. Dessa maneira, temos uma atenção maior sendo concedida aos direitos civis e individuais, engendrando uma judicialização da vida: 
O que hoje se observa é a multiplicação dos objetos judiciáveis, a redefinição do sentido da violência, o que significa também a multiplicação das atribuições judiciárias. Posso citar algumas: questões referentes à mídia, família, internações, trabalho, à constitucionalidade, questões sanitárias, referentes ao consumo, às mulheres, às crianças, às discriminações de minorias, à informação de arquivos que devem ou não vir a público e assim por diante - regulamentação jurídica de todos os comportamentos como modalidade de governo. Parece estar acontecendo um processo de inversão do poder judiciário em comparação com o século XIX, quando uma rede institucional não judiciária desempenhava funções (Foucault, 2005, p. 86) que hoje estão sendo gradativamente atribuídas à justiça. O controle dos comportamentos e das populações continua funcionando nesta rede de vigilância e correção em instituições como a escolar, a polícia, a psiquiatria, mas certamente vem transferindo seu poder decisório e seu objetivo de prevenir e corrigir as virtualidades da infração para o poder judiciário. Percebe-se hoje em dia um clamor por leis mais duras e corretivas para evitar que mulheres sejam espancadas, crianças levem palmadas, minorias sejam desrespeitadas, para evitar acidentes de trânsito, e assim por diante, ou seja, a lei cumprindo função pedagógica de mudanças de comportamento. (Lobo, 2012, p. 29, grifo nosso)

No projeto Saúde e Prevenção nas Escolas, variadas leis são mencionadas, como forma de sustentar os seus enunciados sobre quais comportamentos devem ser estimulados e quais devem ser evitados pelos jovens. Sobre a violência de gênero, por exemplo, o professor é orientado a evocar a lei Maria da Penha durante uma oficina sobre violência com os adolescentes:

A partir das definições levantadas pelo grupo, explique que: No artigo $5^{\circ}$ da Lei Maria da Penha, a lei que trata sobre a violência contra a mulher, configura-se como violência doméstica e familiar qualquer ação ou omissão baseada no gênero que lhe cause morte, lesão, sofrimento físico, sexual ou psicológico, e danos morais ou patrimoniais. (Min. da Saúde, 2011 a, p. 41)

A judicialização da vida é clamada de forma velada. Não percebemos que ora ou outra estamos chamando a justiça, as leis, o conselho tutelar e outros órgãos para nos respeitar "custe o que custar", como se a lei por si só garantisse o respeito ao outro. Além disso, percebemos leis mais duras, mais coercitivas e mais capilares, para cumprir funções pedagógicas que antes eram desempenhadas por outras instâncias. Nos materiais do projeto analisado aqui, é possível observar que a questão do preconceito, algo do âmbito do julgamento moral, adentra o campo penal: "No Estado de São Paulo, a Lei No 10.948, de 5/11/2001, em seu artigo, $1^{\circ}$ diz o seguinte: será punida toda manifestação atentatória ou discriminatória contra cidadão homossexual, bissexual ou transgênero (travesti, transexual)." (Min. da Saúde, 2011 b, p. 45).

De um modo ou de outro, construímos mecanismos para reivindicar e garantir nossos clamados "direitos". Uma gama cada vez maior de pessoas amplia:

os tentáculos do Poder Judiciário, judicializando a vida em nome do conforto e da tranquilidade de todos. Cada vez mais situações são encaminhadas para a chamada “justiça”, multiplicando-se as áreas e os tipos de profissionais que a habitam, sob a crença que estando em mãos da "justiça” o bem será feito e a verdade reinará. A sociedade disciplinar se apoia nos direitos, produzidos como normas universais, 
como se fossem neutros, definindo o sujeito de direito: o cidadão. Esse, sublimado na sociedade burguesa, é o homem da norma, da disciplina. (Scheinvar, 2012, p. 45)

Destarte, devemos também problematizar como essa lei é aclamada dentro dos documentos do SPE. Em um dos documentos, afirma-se: "As leis existem para garantir os direitos das pessoas e, por esta razão, adolescentes e jovens necessitam conhecê-las para poder se posicionar em situações em que haja discriminação e/ou preconceito." (UNESCO \& MEC, 2010a, p. 86). Cabe a pergunta: que sujeitos "jurídicos" estamos produzindo? Que judicialização estamos propagando? Será que relações com a diversidade/diferença baseada quase que exclusivamente pela via jurídica não acabaria por esvaziar a possibilidade de problematização do atravessamento das diferenças em nós mesmos?

\section{Considerações finais}

Os documentos do SPE não somente produzem um domínio de saber sobre a diversidade sexual. Não somente fazem aparecer novas técnicas, objetos, conceitos e formas para lidar com os mais diversos conteúdos, "mas também faz nascer formas totalmente novas de sujeitos e de sujeitos do conhecimento" (Foucault, 2002, p. 8). Assim, podemos afirmar que estes documentos definem formas de relações entre os sujeitos e que, exatamente por tal motivo, torna-se necessário problematizar os seus efeitos.

Este estudo considera que "a hegemonia do mito científico como fonte de sentido invade o modo como os indivíduos se apropriam de sua experiência subjetiva” (Bezerra, 2002, p. 235). Dessa maneira, indicamos que o discurso sobre diversidade sexual parece elucidar um sujeito fundado nos ideais dos direitos humanos, que promovem a igualdade e combate aos preconceitos e às discriminações com relação às diversidade(s) sexuai(s). Mas, o que está em jogo?

Segundo o SPE, sendo parte de uma minoria e ocupando um lugar de outro, o "adolescente da diversidade" deve ser respeitado em sua identidade e, embora seja "diferente", deve ter os seus direitos universais garantidos. Os discursos presentes no SPE proclamam a igualdade e o respeito à diferença. É um duplo jogo: já que somos juridicamente iguais, temos que respeitar os que são diferentes. Neste sentido, a diversidade sexual é defendida e respeitada a partir do discurso jurídico da igualdade. Ainda assim, esse discurso parece problemático, já que tanto pode corroborar com as distinções quanto pode combatê-las.

Além disso, vemos um discurso que talvez possa caracterizar-se como jurídico-penal, uma vez que se apresenta impregnado de uma busca pelo cumprimento das diversas leis que protegem os direitos à diversidade sexual. Questões que outrora eram reguladas por normas agora se encontram contempladas por leis, como o preconceito e a discriminação.

Importante ainda apontar que não se trata aqui de uma análise de caráter moral ou avaliativo do discurso jurídico acerca da diversidade sexual apresentado nos materiais documentais do projeto Saúde e Prevenção nas Escolas, uma vez que não é desse tipo de perspectiva teórico-metodológica que partimos. O intuito foi mostrar como as coisas acontecem dentro desse nosso corpus escolhido, mapeando as tramas do discurso, identificando o que é dito, quando é dito e em nome de quê é dito. Tratou-se de levantar questionamentos, desalojar certezas e indicar algumas interrogações sobre que diversidade sexual se quer quando se fala em nome de um discurso jurídico. 


\section{Referências}

Altmann, H. (2001). Orientação sexual nos parâmetros curriculares nacionais. Rev. Estud. Fem.9(2), 575-585.

Altmann, H. (2006). Sobre a educação sexual como um problema escolar. Linhas (UDESC), 7(1), $1-12$.

Altmann, H. (2007). A sexualidade adolescente como foco de investimento político-social. Educação em Revista, 46, 287-310.

Altmann, H. \& Martins, C. J. (2009). Educação sexual: ética, liberdade e autonomia. Educar, 35, $63-80$

Araújo, I. L. (2004). A noção de discurso em Foucault. In Do signo ao discurso: introdução à filosofia da linguagem (pp. 215-244). São Paulo: Parábola.

Bezerra, B. C. (2002). O ocaso da interioridade e suas repercussões sobre a clínica. In C. A., Plastino (Org.), Transgressões (pp. 229-239). Rio de Janeiro: Contracapa.

Castro, E. (2009). Vocabulário de Foucault: um percurso pelos seus temas, conceitos e autores. Belo Horizonte: Autêntica Editora.

Deleuze, G. (2005). Foucault. São Paulo: Brasiliense.

Dinis, N. \& Asinelli-luz, A. (2007). Educação Sexual na perspectiva histórico-cultural. Educar, 30, $77-87$.

Fairclough, N. (2001). Discurso e mudança social. Brasília, DF: Editora Universidade de Brasília.

Foucault, M. (1984). História da sexualidade: o uso dos prazeres. Rio de Janeiro: Edições Graal.

Foucault, M. (1985). História da sexualidade: o cuidado de si. Rio de Janeiro: Edições Graal.

Foucault, M. (1986). A Arqueologia do saber. Rio de Janeiro: Forense.

Foucault, M. (1988). História da sexualidade: a vontade de saber. Rio de Janeiro: Edições Graal.

Foucault, M. (201 1). Vigiar e Punir: o nascimento da prisão. Petrópolis, RJ: Vozes.

Foucault, M. (2012). A ordem do discurso: aula inaugural no Collège de France, pronunciada em 2 de dezembro de 1970 (22a ed.). São Paulo: Edições Loyola.

Junqueira, R. D. (2009). Homofobia nas escolas: um problema de todos. In Diversidade sexual na educação: problematizações sobre a homofobia nas escolas (pp. 13-52). Brasília, DF: Ministério da Educação.

Lafer, C. (1995). A ONU e os direitos humanos. Estudos Avançados, 9(25), 169-185.

Lobo, L. F. (2012). A expansão dos poderes judiciários. Psicologia \&̊ Sociedade,24(n.spe.) 25-30.

Maliska, M. A. \& Wolochn, R.F. (2013). Reflexões sobre o princípio da tolerância. Revista da Faculdade de Direito UFPR, 58, 37-52.

Ministério da Educação. (1997). Parâmetros curriculares nacionais: introdução aos parâmetros curriculares nacionais. Brasília, DF: Autor.

Ministério da Saúde. (2004). Brasil sem Homofobia: Programa de combate à violência e à discriminação contra GLTB e promoção da cidadania homossexual. Brasília, DF: Autor.

Ministério da Saúde. (2006). Saúde e prevenção nas escolas: guia para a formação de profissionais de saúde e de educação. Brasília, DF: Autor. 
Ministério da Saúde. (2007). Marco Legal: saúde um direito de adolescentes. Brasília, DF: Autor.

Ministério da Saúde. (2011a). Gêneros: adolescentes e jovens para a educação entre pares. Brasília, DF: Autor.

Ministério da Saúde. (2011b). Adolescentes e jovens para a educação entre pares: diversidades sexuais. Brasília, DF: Ministério da Saúde.

Ministério da Saúde. (2011c). Adolescentes e jovens para a educação entre pares: sexualidades e saúde reprodutiva. Brasília, DF: Autor.

Ministério da Saúde. (2011d). Adolescentes e jovens para a educação entre pares: adolescência, juventudes eparticipação. Brasília, DF: Autor.

Ministério da Saúde. (2011e). Adolescentes e jovens para a educação entre pares: raças e etnias. Brasília, DF: Autor.

Ministério da Saúde. (201 1f). Adolescentes e jovens para a educação entre pares: prevenção das DST, HIV e Aids. Brasília, DF: Autor.

ONU. (1948). Declaração Universal dos Direitos Humanos. Recuperado de https://nacoesunidas. org/wp-content/uploads/2018/10/DUDH.pdf

Organização das Nações Unidas para a Educação, a Ciência e a Cultura (UNESCO) \& Ministério da Educação (MEC). (2010a). HQ SPE: um guia para utilização em sala de aula. Brasília, DF: Autores.

Organização das Nações Unidas para a Educação, a Ciência e a Cultura (UNESCO) \& Ministério da Educação (MEC). (2010b). HQ SPE N 1: Perguntas e Respostas Parte 1 e 2. Brasília, DF: Autores.

Organização das Nações Unidas para a Educação, a Ciência e a Cultura (UNESCO) \& Ministério da Educação (MEC). (2010c). HQ SPE $N^{o}$ 2: Todas as Claudinhas do mundo e DS... O QUÊ?Brasília, DF: Autores.

Organização das Nações Unidas para a Educação, a Ciência e a Cultura (UNESCO)\& Ministério da Educação (MEC). (2010d). HQ SPE $N^{o}$ 3: a Vida Como Está e as Coisas Como São e Vamos Conversar? Brasília, DF: Autores.

Organização das Nações Unidas para a Educação, a Ciência e a Cultura (UNESCO) \& Ministério da Educação (MEC). (2010e). HQSPE $N^{o}$ 4: Ficar ou não Ficar? Partes 1 e 2. Brasília, DF: Autores.

Organização das Nações Unidas para a Educação, a Ciência e a Cultura (UNESCO) \& Ministério da Educação (MEC). (2010f). HQ SPE Nº B: Balada. Brasília, DF: Autores.

Organização das Nações Unidas para a Educação, a Ciência e a Cultura (UNESCO) \& Ministério da Educação (MEC). (2010g). HQ SPE Nº Cena de cinema e Perguntas e Respostas Parte 3. Brasília, DF: Autores.

Petry, A. R. \& Meyer, D. E. E. (2011) Transexualidade e heteronormatividade: algumas questões para a pesquisa. Textos $\mathcal{E}$ Contextos, $10(1), 193-198$.

Pierucci, A. F. (1999). As ciladas da diferença. São Paulo: Ed.34.

Quartiero, E. T. \& Nardi, H. C. (2011). A Diversidade Sexual na Escola: produção de subjetividade e políticas públicas. Revista Mal-estar e Subjetividade, 11(2), 701-725.

Santos, C., Ramos, M. E. C., Timm, F. B., Cabral, D. G., \& Lobo, T. D. M. (2008). Diversidade sexual na escola e a homofobia: a capacitação de professores como estratégia de intervenção. In Seminário Internacional Fazendo o Gênero VIII, Anais(p. 105-123). Florianópolis, SC: UFSC. Recuperado de https://www.academia.edu/5281870/Diversidade sexual na escola e a 
homofobia a capacita\%C3\%A7\%C3\%A30 de professores como estrat\%C3\%A9gia de interven $\% \mathrm{C} 3 \% \mathrm{~A} 7 \% \mathrm{C} 3 \% \mathrm{~A} 30$

Scheinvar, E. (2012). Conselho tutelar e escola: a potência da lógica penal no fazer cotidiano. Psicologia Ẽ Sociedade, 24(n.spe.), 45-51.

Secretaria Especial de Política para as Mulheres. (2004). Plano Nacional de Políticas para as Mulheres. Brasília, DF: Autor.

Secretaria Especial de Direitos Humanos. (2007). Comitê Nacional de Educação em Direitos Humanos. Plano Nacional de Educação em Direitos Humanos. Brasília, DF: Autor.

Senado Federal. (1988). Constituição da República Federativa do Brasil. Brasília, DF: Autor.

Veiga-Neto, A. (2009). Teoria e Método em Michel Foucault: (im)possibilidades. Cadernos de Educação, 1(34), 11-23.

\section{NATHÁSSIA MATIAS DE MEDEIROS \\ https://orcid.org/0000-0003-1766-2388}

Mestre em Psicologia pela Universidade Federal do Ceará, linha Cultura e Sujeito na Contemporaneidade com bolsa da Fundação Cearense de Apoio ao Desenvolvimento Científico e Tecnológico (FUNCAP). Doutoranda em Psicologia pela Universidade Federal do Ceará. Membro do Laboratório em Psicologia, Subjetividade e Sociedade (LAPSUS).

Endereço institucional: Av. da Universidade, 2762, Benfica - CEP: 60.020180 - Fortaleza/CE - Área 2 do Centro de Humanidades - Bloco Didático Prof. Ícaro de Sousa Moreira.

E-mail: nathassiamm@gmail.com

\section{LORRANA CALIOPE CASTELO BRANCO MOURÃO}

https://orcid.org/0000-0003-2892-5550

Mestre em Psicologia pela Universidade Federal do Ceará, linha Cultura e Sujeito na Contemporaneidade e doutoranda em Psicologia pela Universidade Federal do Ceará. Atualmente está realizando doutorado co-tutela na Vrije Universiteit Brussel (VUB) na Bélgica, contemplada com bolsa CAPES. Membro do Laboratório em Psicologia, Subjetividade e Sociedade (LAPSUS).

E-mail: loccbm@gmail.com

\section{LUCIANA LOBO MIRANDA}

\section{https://orcid.org/0000-0002-7838-8098}

Doutora em Psicologia pela PUC-RJ, com estágio doutoral no Programa de Ciência da Educação em Paris 8, França; estágio pós-doutoral no Programa de Psicologia Social Crítica e Personalidade pela City University of New York (CUNY), EUA. Professora associada do Programa de Pós-graduação em Psicologia da Universidade Federal do Ceará (UFC). Vice-coordenadora do PPG-Psicologia UFC. Coordenadora do Laboratório em Psicologia, Subjetividade e Sociedade (LAPSUS).

E-mail: lobo.lu@uol.com.br 


\begin{tabular}{|c|c|}
\hline Histórico & $\begin{array}{l}\text { Submissão: 29/01/2017 } \\
\text { Revisão: 09/12/2019 } \\
\text { Aceite: 12/02/2020 }\end{array}$ \\
\hline Contribuição & $\begin{array}{l}\text { Concepção: N.M.M; L.C.C.B.M; L.L.M. } \\
\text { Coleta de dados: N.M.M; L.C.C.B.M; L.L.M. } \\
\text { Análise de dados: N.M.M; L.C.C.B.M; L.L.M. } \\
\text { Elaboração do manuscrito: N.M.M; L.C.C.B.M; L.L.M. } \\
\text { Crítico revisões de conteúdo intelectual importante: } \\
\text { N.M.M; L.C.C.B.M; L.L.M. } \\
\text { Final aprovação do manuscrito: N.M.M, L.C.C.B.M, L.L.M. }\end{array}$ \\
\hline Financiamento & $\begin{array}{l}\text { O mestrado da autora Nathássia Matias de Medeiros, durante } \\
\text { o qual foi realizada a pesquisa que originou este artigo, foi } \\
\text { financiado pelo Programa de Bolsas de Formação Acadêmica } \\
\text { - Mestrado e Doutorado da Fundação Cearense de Apoio ao } \\
\text { Desenvolvimento Científico e Tecnológico. (FUNCAP) } \\
\text { O mestrado da coautora Lorrana Caliope Castelo Branco } \\
\text { Mourão, durante o qual foi realizada a pesquisa que } \\
\text { contribui com este artigo, foi financiado pelo Programa de } \\
\text { Demanda Social da Agência do Governo Coordenação de } \\
\text { Aperfeiçoamento de Pessoal de Nível Superior (CAPES). }\end{array}$ \\
\hline
\end{tabular}

